\title{
PRODUKSI BIOETANOL SECARA SHF DAN SSF MENGGUNAKAN Aspergillus niger, Trichoderma viride DAN New Aule Instant Dry Yeast PADA MEDIA KULIT UBI KAYU
}

Separated Hydrolysis and Simultaneous Saccharification for Production of Bioethanol from Aspergillus niger, Trichoderma viride and New Aule Instant Dry Yeast Using Cassava Peels as Substrate

\author{
Jay Jayus ${ }^{1,2) *}$, Sony Suwasono ${ }^{1)}$, Ike Wijayanti ${ }^{1)}$ \\ ${ }^{1)}$ Jurusan Teknologi Hasil Pertanian - Fakultas Teknologi Pertanian, Universitas Jember \\ ${ }^{2)}$ Centre for Development of Advance Science and Technology, Universitas Jember \\ Jalan Kalimantan 37, Kampus Tegal Boto Jember 68121 \\ *E-mail: jayus.ftp@unej.ac.id
}

\begin{abstract}
Effort to improve the yield of bioetanol production from cassava peels were be carried out by separated hydrolysis fermentation (SHF) and simultaneous saccharification fermentation (SSF) using Aspergillus niger, Trichoderma viride and New Aule Instant Dry Yeast. The purpose of this research is to measure bioetanol production from cassava peels using three different culture methods i.e SHF1 (A. niger 24 hours + New Aule Instant Dry Yeast); SHF2 (T. viride 24 hours + New Aule Instant Dry Yeast); and SSF (A. niger+ T. viride+New Aule Instant Dry Yeast). The research results showed SHF1 $(2,58 \mathrm{~g} / \mathrm{l})$ produced higher ethanol than that of SHF2 $(2,15)$. The methods of SSF eficiency produced ethanol $(2,93 \mathrm{~g} / \mathrm{l})$ and faster (18 hours) compared the methods of SHF1 and SHF2 which need 48 hours incubation time to reach maximum level.
\end{abstract}

Keywords: Bioethanol, cassava peels, SHF, SSF, A.niger, T.viride, new Aule

\section{PENDAHULUAN}

Bahan bakar fosil merupakan energi utama yang tidak dapat terbaharukan dan setiap tahunnya konsumsi bahan bakar mengalami peningkatan. Berdasarkan data total konsumsi energi didunia tahun 20052014 mengalami peningkatan dari 995,1 juta barel/hari menjadi 1.186,2 juta barel/hari, sedangkan di Indonesia sendiri pada tahun 2000 konsumsi bahan bakar sebesar 315 juta barel dan meningkat pada tahun 2013 menjadi 399 juta barel (International Annual Energy Outlook (2013); BPTP (2015)). Salah satu upaya untuk mengatasi hal tersebut yaitu mencari energi alternatif seperti bioetanol.

Bioetanol adalah etanol yang dihasilkan dari fermentasi glukosa dengan bantuan Saccharomyces cerevisiae (Khaidir et al., 2012). Bioetanol dapat digunakan sebagai pengganti bahan bakar minyak tergantung dari tingkat kemurniannya. Bioetanol dengan kadar 9599\% dapat sebagai bahan substitusi premium (bensin), sedangkan kadar $40 \%$ dapat sebagai bahan substitusi minyak tanah. Bioetanol dapat diproduksi dari beberapa jenis media yang mengandung gula, pati, selulosa, dan bahan berserat (lignoselulosa).

Ubi kayu merupakan salah satu sumber bahan pangan dengan kandungan karbohidrat yang cukup tinggi setelah padi dan jagung. Menurut data BPS (2015), produksi ubi kayu nasional telah mencapai 21.790.956 ton dan menghasilkan limbah dengan jumlah yang tinggi, salah satunya limbah kulit ubi kayu. Menurut Grace (1977), persentase kulit ubi kayu yang dihasilkan berkisar antara $8-15 \%$ dari berat umbi yang dikupas. Kulit ubi kayu mengandung komponen selulosa 43,626\%, hemiselulosa $36,58 \%$, dan pati $10,384 \%$ 
yang berpotensi sebagai bahan baku bioetanol (Artiyani dan Soedjono, 2011).

Tahapan produksi bioetanol

berbahan lignoselulosa seperti kulit ubi kayu terdiri dari tahapan preatreatment (delignifikasi), hidrolisis dan fermentasi. Proses pretreatment atau delignifikasi biomassa berlignoselulosa bertujuan untuk menghilangkan sisa lignin yang dapat menghambat kerja enzim (Fengel dan Wegener, 1995). Proses hidrolisis dapat dilakukan secara kimiawi dan enzimatik. Dalam menghasilkan glukosa, hidrolisis secara kimiawi menggunakan larutan asam akan memotong ikatan secara acak. Hidrolisis enzimatik dilakukan dengan menggunakan enzim $\alpha$-amilase, selulase, dan xilanase yang dapat disintesis dari beberapa mikroorganisme seperti Trichoderma viride dan Aspergillus niger (Nakasaki dan Adachi, 2003). Berdasarkan hal tersebut kedua jenis mikroorganisme tersebut dapat digunakan dalam proses hidrolisis komponen kulit ubi kayu.

Fermentasi bioetanol dapat dilakukan dengan menggunakan metode separated hydrolysis fermentation (SHF) dan simultaneous saccharification fermentation (SSF). Penggunaan metode fermentasi SHF dapat dilakukan pada masing-masing kondisi optimum, sedangkan penggunaan metode SSF dapat mencegah terhambatnya kerja enzim oleh produk glukosa dan selobiosa yang selama ini menjadi kelemahan dari metode pembuatan etanol secara SHF (Taherzadeh dan Karimi, 2007; Olofsson et al., 2008). Berdasarkan hal tersebut produksi bioetanol kulit ubi kayu menggunakan $A$. niger, $T$. viride dan new aule instant dry yeast secara SHF dan SSF perlu diteliti sebagai upaya meningkatkan produksi bioetanol.

\section{METODE PENELITIAN}

\section{Alat dan Bahan}

Alat-alat yang digunakan dalam penelitian ini adalah alat gelas, oven, blender, ayakan Tyler 100 mesh, Laminar Air Flow (Microtech Model V3), fermentor, sentrifus, spektrofotometer (Genesys 10 UV), autoklaf Sturdy (SA 3000VL), inkubator (Scientific Series 2000), orbital shaker inkubator (Wise Cube ${ }^{(\mathbb{B})}$, Haemacytometer, mikroskop, hand $\mathrm{pH}$ meter dan cawan conway.

Bahan yang digunakan adalah kulit ubi kayu (Pabrik Pengolahan Tape Sari Madu Gebang Kab. Jember) dan bahan kimia yang digunakan adalah $\mathrm{NaOCl} 1 \%$, yeast extract, $\mathrm{NaOH}$, Asam sitrat, mineral salt solution, MEA, $\left(\mathrm{NH}_{4}\right)_{2} \mathrm{SO}_{4}$, glukosa, $\mathrm{K}_{2} \mathrm{Cr}_{2} \mathrm{O}_{7}, \mathrm{H}_{2} \mathrm{SO}_{4}$, fenol, etanol dan DNS. Mikroorganisme yang digunakan diantaranya $A$. niger, $T$. viride dan New Aule Instant Dry Yeast.

\section{Tahapan Penelitian}

Pembuatan tepung kulit ubi kayu

Kulit ubi kayu dibersihkan kulit terluar yang berwarna coklat dan dicuci bersih. Kemudian dilakukan pengeringan dengan metode sundrying selama 24 jam untuk mengurangi kadar air. Selanjutnya dilakukan pengecilan ukuran menggunakan blender dan diayak menggunakan ayakan 100 mesh. Tepung kulit yang dihasilkan didelignifikasi menggunakan $\mathrm{NaOCl} 1 \%$ selama 5 jam pada suhu $30^{\circ} \mathrm{C}$ (Assadam, 2014).

\section{Pembuatan starter A.niger dan T.viride}

Media inokulum yang terdiri dari $0,5 \mathrm{~g} / \mathrm{L}$ tepung ubi kayu, $0,3 \mathrm{~g} / \mathrm{L}$ yeast extract, $0,6 \mathrm{~g} / \mathrm{L}\left(\mathrm{NH}_{4}\right)_{2} \mathrm{SO}_{4}, 50 \mathrm{ml} / \mathrm{L}$ mineral salt solution. Selanjutnya di sterilkan pada $121^{\circ} \mathrm{C}$ selama 15 menit, setelah itu inokulasi kultur $A$. niger dan $T$. viride (masing-masing 3 tabung reaksi). Selanjutnya inkubasi pada $150 \mathrm{rpm}$ selama 24 jam dengan suhu $30^{\circ} \mathrm{C}$. Selanjutnya dilakukan pemisahan sel pada suhu $10{ }^{\circ} \mathrm{C}$ selama 10 menit dan dilakukan pencucian 2 kali menggunakan aquades steril sehingga di hasilkan sel. Sel dipindahkan ke dalam gelas ukur dan di tambah aquades steril hingga volume tertentu. 
Pembuatan starter new aule instant dry yeast

Starter dari ragi roti instan New Aule Instant Dry Yeast 1\% (w/v) dari jumlah media yang digunakan dalam fermentasi, kemudian dicampur dengan $2 \%$ larutan glukosa steril $50 \mathrm{ml}$ pada suhu $\pm 42^{\circ} \mathrm{C}$ dan didiamkan selama 3 jam (Arindhani, 2015).

\section{Produksi Bioetanol}

Media kulit ubi kayu yang terdiri atas kulit ubi kayu $10 \mathrm{~g} / 1$, yeast extract $0,3 \mathrm{~g} / \mathrm{L}$, mineral salt solution $50 \mathrm{ml} / \mathrm{L}$ dan $\left(\mathrm{NH}_{4}\right)_{2} \mathrm{SO}_{4}$ 0,6g/L. Selanjutnya dilakukan pengaturan $\mathrm{pH} \pm 4,5$ dan sterilisasi pada $121^{\circ} \mathrm{C}$ selama 15 menit. Selanjutnya dilakukan inokulasi biakan $A$. niger atau $T$. viride selanjutnya diinkubasi selama 24 jam. Setelah 24 jam dilakukan inokulasi New Aule Instant Dry Yeast diinkubasi hingga 48 jam untuk menghasilkan etanol. Pada SSF dilakukan inokulasi A. niger, $T$. viride dan New Aule Instant Dry Yeast secara bersamaan diinkubasi hingga 48 jam.

\section{Rancangan Percobaan}

Penelitian ini dilakukan dengan faktor tunggal yaitu metode kultur fermentasi dengan perlakuan SHF1 ( $A$. niger+ New Aule Instant Dry Yeast), SHF2 (T. viride+ New Aule Instant Dry Yeast) dan SSF (A. niger+ T. viride+ New Aule Instant Dry Yeast).

\section{Metode Analisis}

Parameter yang diamati dalam penelitian ini meliputi: perhitungan massa sel metode berat kering, populasi yeast metode Counting Chamber (Lay, 1994), total gula terlarut metode fenol sulfat (Dubois, 1956), analisis gula reduksi metode dinitrosalisilic acid (DNS) (Miller, 1959), derajat $\mathrm{pH}$, dan kadar etanol metode Chamber Conway (Kartika et al., 1992). Data yang diperoleh disajikan dalam bentuk tabel, grafik dan histogram dengan hasil penyelesaian berupa rata-rata dan standart deviasi.

\section{HASIL DAN PEMBAHASAN}

\section{Profil Hidrolisis SHF1 dan SHF2 pada Media Kulit Ubi Kayu}

Massa sel, total gula terlarut dan gula reduksi pada proses hidrolisis mengalami peningkatan hingga 24 jam (Gambar 1). Glukosa yang dihasilkan saat proses hidrolisis selanjutnya di fermentasi untuk menghasilkan etanol (Gambar 2).
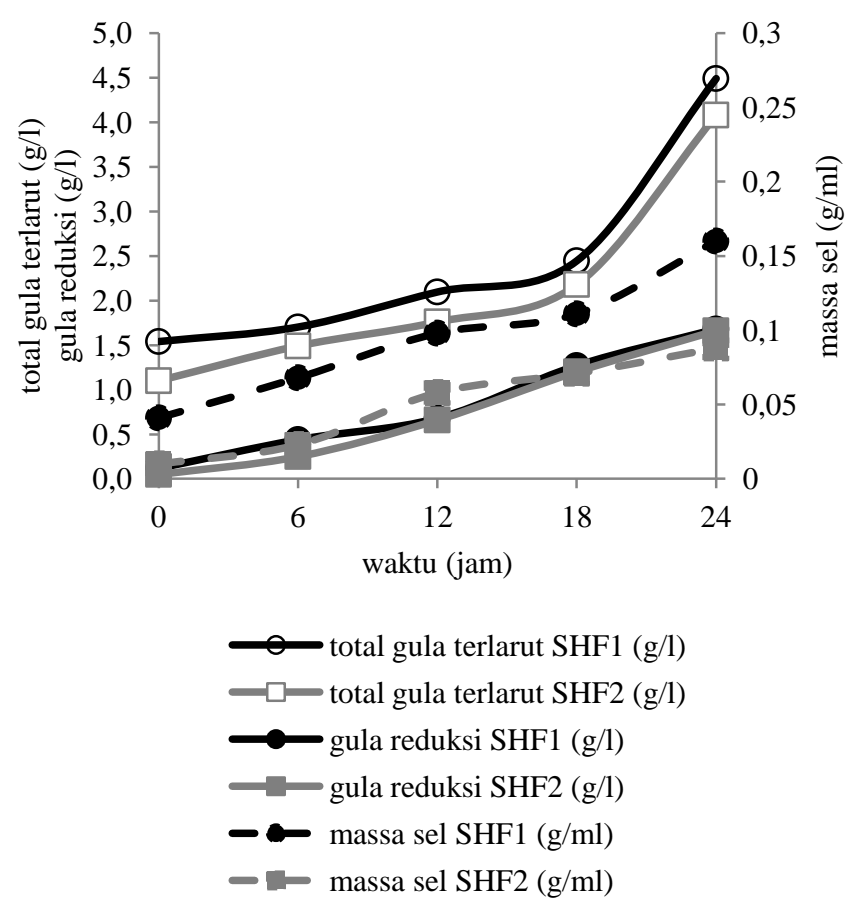

Gambar 1. Hubungan antara peningkatan massa sel $(\mathrm{g} / \mathrm{ml})$, peningkatan total gula terlarut $(\mathrm{g} / \mathrm{l})$ dan gula reduksi $(\mathrm{g} / \mathrm{l})$ selama hidrrolisis SHF1 dan SHF2 pada media kulit ubi kayu

Hasil massa sel SHF1 dan SHF2 pada 0 jam masing-masing sebesar $0,041 \mathrm{~g} / \mathrm{ml}$ dan $0,01 \mathrm{~g} / \mathrm{ml}$. Pada 24 jam hidrolisis mengalami fase logaritmik (fase pertumbuhan sel hingga mencapai jumlah maksimum) pada SHF1 sebesar $0,16 \mathrm{~g} / \mathrm{ml}$ dan pada SHF2 sebesar 0,088 $\mathrm{g} / \mathrm{ml}$. Peningkatan massa sel dapat dipengaruhi oleh kondisi media hidrolisis baik nutrisi, $\mathrm{pH}$, suhu dan oksigen (Gandjar et al., 2006). 
Total gula terlarut dan gula reduksi pada 0 jam masing-masing perlakuan secara berurutan pada SHF1 sebesar 1,54 $\mathrm{g} / \mathrm{l}$ dan $0,12 \mathrm{~g} / \mathrm{l}$ sedangkan pada SHF2 sebesar 1,1 g/l dan 0,05 g/l. Pada 24 jam hidrolisis total gula dan gula reduksi mengalami peningkatan masing-masing pada SHF1 sebesar 4,490 g/l dan 1,68 g/l sedangkan SHF2 masing-masing sebesar 4,08 g/l dan 1,66 g/l. Hasil menunjukkan total gula terlarut dan gula reduksi pada sampel SHF1 lebih tinggi dibandingkan dengan sampel yang menggunakan SHF2. Hal tersebut disebabkan A. niger mampu menghasilkan enzim selulase, xilanase dan $\alpha$-amilase yang mampu memecah komponen selulosa, hemiselulosa dan pati dalam tepung kulit ubi kayu.

\section{Profil Fermentasi Bioetanol SHF1 dan SHF2 pada Media Kulit Ubi Kayu}

Gula yang dihasilkan saat hidrolisis selanjutnya digunakan untuk proses fermentasi. Hasil disajikan dalam Gambar 2.

Hasil massa sel SHF1 pada 0 jam fermentasi sebesar $0,271 \mathrm{~g} / \mathrm{ml}$ meningkat hingga 30 jam fermentasi sebesar 0,501 $\mathrm{g} / \mathrm{ml}$ dan mulai menurun setelah 30 jam fermentasi hingga 48 jam fermentasi. Sedangkan massa sel SHF2 pada 0 jam fermentasi sebesar $0,256 \mathrm{~g} / \mathrm{ml}$ meningkat hingga 30 jam fermentasi sebesar 0,464 $\mathrm{g} / \mathrm{ml}$.

Etanol yang dihasilkan SHF1 dan SHF2 maksimum selama 18 hingga 24 jam fermentasi. Pada sampel SHF1 etanol yang dihasilkan pada 18 dan 24 jam fermentasi secara berurutan sebesar $2,1 \mathrm{~g} / \mathrm{l}$ dan 2,58 g/l, sedangkan pada sampel SHF2 sebesar $1,89 \mathrm{~g} / \mathrm{l}$ dan 2,15 $\mathrm{g} / \mathrm{l}$. Hal tersebut dikarenakan A. niger dapat menghasilkan enzim selulase, xilanase dan $\alpha$-amilase yang dapat menghidrolisis selulosa, hemiselulosa dan pati sehingga menghasilkan gula yang lebih tinggi dibandingkan dengan $T$. viride yang hanya mampu menghasilkan enzim selulase dan xilanase sehingga komponen yang dapat terhidrolisis hanya selulosa dan hemiselulosa.
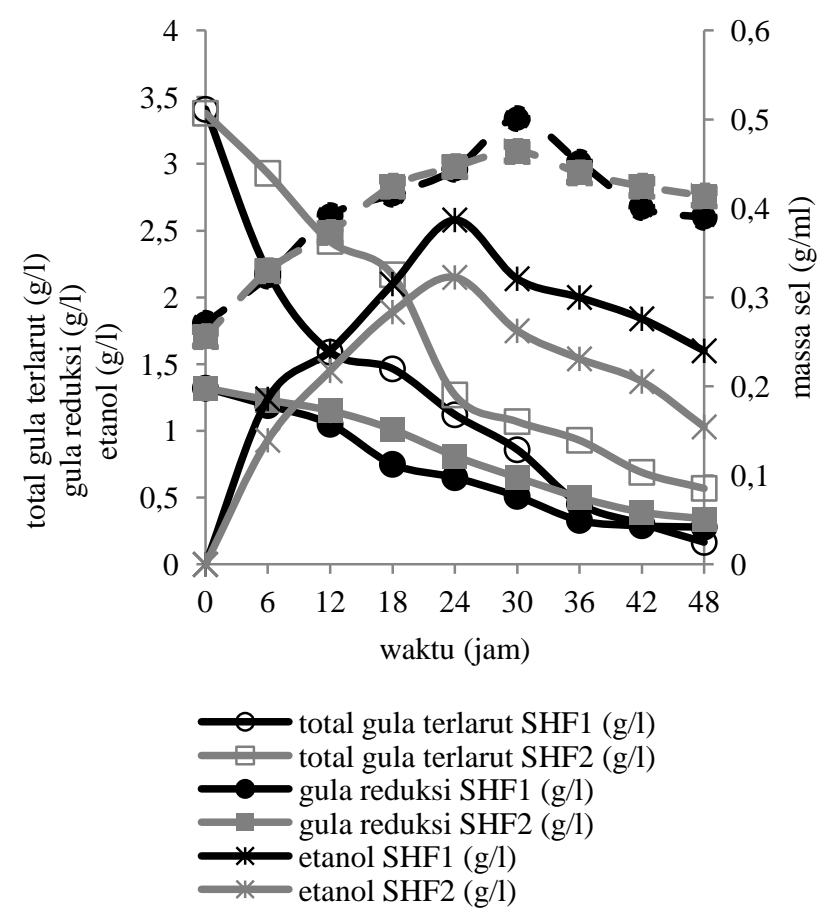

Gambar 2. Hubungan antara peningkatan massa sel $(\mathrm{g} / \mathrm{ml})$, peningkatan etanol $(\mathrm{g} / \mathrm{l})$, penurunan jumlah total gula terlarut (g/l) dan penurunan gula reduksi $(\mathrm{g} / \mathrm{l})$ selama proses fermentasi bioetanol SHF1 dan SHF2 pada media kulit ubi kayu.

Jumlah etanol pada masing-masing sampel mulai megalami penurunan setelah 24 hingga 48 jam fermentasi. Hal tersebut menunjukkan dengan semakin lamanya fermentasi akan meningkatkan jumlah alkohol yang dihasilkan, namun lamanya proses fermentasi memiliki batas maksimum (Judoamidjojo et al., 1992). Menurut Mayzuhroh (2015), penurunan kadar alkohol disebabkan ketersediaan substrat berupa gula mulai menurun dan telah habis digunakan, selain itu yeast yang digunakan telah memasuki fase kematian sehingga kemampuan yeast untuk mengkonfersi gula menjadi etanol menurun. 


\section{Profil Fermentasi Bioetanol Metode SSF Pada Media Kuli Ubi Kayu}

Hasil menunjukkan terjadi peningkatan massa sel yang diikuti dengan meningkatnya total gula terlarut, gula reduksi dan etanol (Gambar 3).

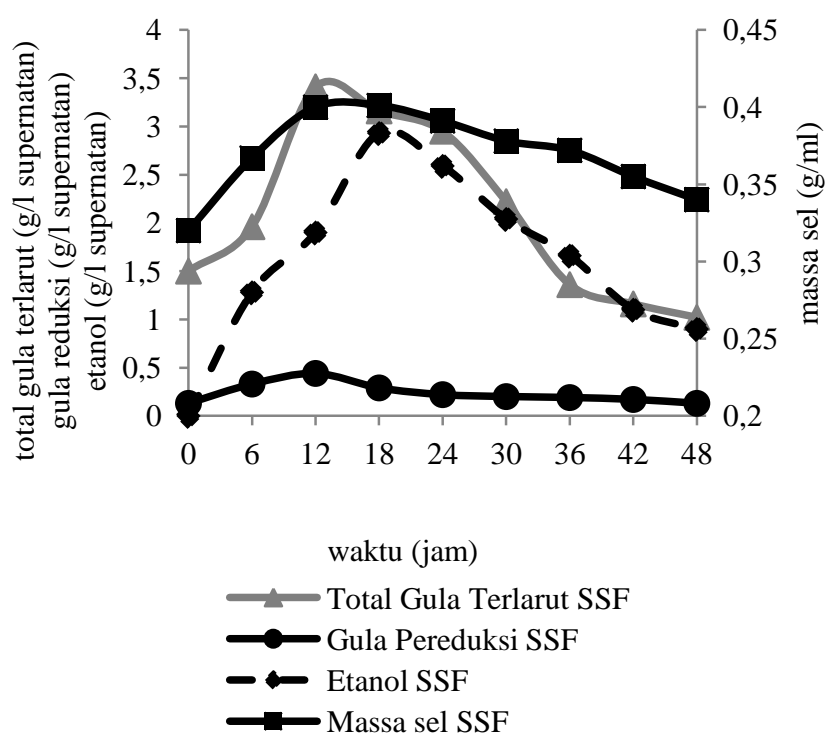

Gambar 3. Hubungan antara peningkatan dan penurunan massa sel $(\mathrm{g} / \mathrm{ml})$, total gula terlarut $(\mathrm{g} / \mathrm{l})$, gula reduksi $(\mathrm{g} / \mathrm{l})$ dan etanol $(\mathrm{g} / \mathrm{l})$ selama fermentasi bioetanol secara SSF pada media kulit ubi kayu

Massa sel dan etanol mengalami peningkatan hingga 18 jam fermentasi secara berurutan sebesar $0,401 \mathrm{~g} / \mathrm{ml}$ dan 2,93 g/l, sedangkan peningkatan total gula terlarut dan gula reduksi terjadi hingga 12 jam fermentasi masing-masing sebesar $3,41 \mathrm{~g} / \mathrm{l}$ dan $0,44 \mathrm{~g} / \mathrm{l}$. Hal tersebut menunjukkan bahwa $A$. niger dan $T$. viride mampu tumbuh dan berkembang biak secara bersamaan sehingga mampu mengkonversi komponen selulosa, hemiselulosa dan pati kulit ubi kayu untuk menghasilkan gula dan New Aule Instant Dry Yeast langsung menggunakan gula untuk menghasilkan metabolisme berupa etanol. Konsentrasi etanol meningkat dapat disebabkan karena dalam proses fermentasi terjadi proses pemecahan disakarida dan hidrolisa polisakarida menjadi monosakarida atau gula-gula reduksi yang dapat dimanfaatkan oleh khamir (Wignyanto et al., 2001).

Pada Gambar 3 juga menunjukkan bahwa massa sel, total gula terlarut, gula reduksi dan etanol mengalami penurunan hingga 48 jam fermentasi. Penurunan massa sel dan etanol pada 24 jam hingga 48 jam disebabkan karena mikroorganisme mulai memasuki fase kematian sehingga kemampuan untuk menghasilkan gula dan etanol menurun. Menurut Faiqoh (2017), penurunan massa sel menyebabkan kemampuan A. niger dan $T$. viride dalam mengkonversi selulosa, hemiselulosa dan pati semakin menurun sehingga gula yang dihasilkan mengalami penurunan.

\section{Kinetika Fermentasi Bioetanol Secara SHF dan SSF pada Media Kulit Ubi Kayu}

Berdasarkan data pada Tabel 1 dan Tabel 2 dapat diketahui bahwa nilai growth yield pada metode SSF lebih besar daripada nilai growth yield pada metode SHF1 dan SHF2. Hal tersebut disebabkan karena pada metode SSF menggunakan 3 kultur secara langsung sehingga mampu meningkatkan populasi yeast secara cepat, sehingga growth yield pada metode SSF lebih tinggi. Selain itu, growth yield berkaitan dengan jumlah konsumsi gula oleh yeast. yeast dengan jumlah konsumsi gula yang lebih kecil mampu menghasilkan growth yield yang lebih tinggi (Mayzuhroh, 2015).

Nilai laju konsumsi gula reduksi diperoleh dari perbandingan antara konsumsi gula reduksi selama fermentasi dengan lama fermentasi yang berlangsung. Laju konsumsi pada metode SHF1 dan SHF2 hingga akhir fermentasi lebih tinggi dibandingkan dengan metode fermentasi SSF. Ketersediaan substrat berupa gula reduksi pada media fermentasi berkaitan dengan peningkatan populasi yeast.

Jumlah produktivitas etanol merupakan hasil perbandingan antara konsentrasi etanol yang dihasilkan dengan 
lama waktu fermentasi. Produktivitas etanol dapat menunjukkan laju produksi etanol oleh mikroba yang dihasilkan per satuan waktu. Penentuan produktivitas etanol pada masing-masing perlakuan dilakukan pada fase logaritmik atau eksponensial fermentasi. Pada Tabel 1 dapat dilihat bahwa nilai produktivitas etanol maksimum SHF1 dan SHF2 tercapai saat fermentasi 24 jam sedangkan pada Tabel 2 menunjukkan produktivitas etanol maksimum SSF tercapai saat fermentasi 18 jam dan masing-masing mengalami penurunan setelah lama fermentasi tersebut. Penurunan tersebut dikarenakan ketersediaan gula dalam substrat menurun, sehingga kebutuhan nutrisi yeast dalam memproduksi etanol tidak dapat tercukupi secara optimal.

Produktivitas yang dihasilkan masing-masing metode menunjukkan produktivitas SSF lebih tinggi dibanding dengan produktivitas SHF1 dan SHF2. Hal tersebut diduga karena pada metode SSF menggunakan 3 kultur campuran secara simultan yang mampu meningkatkan populasi pertumbuhan yeast sehingga gula reduksi yang terkonversi menjadi etanol lebih banyak. Menurut Mayzuhroh (2015) semakin banyak jumlah populasi yeast maka metabolit berupa enzim alkohol dehidrogenase yang dihasilkan akan semakin banyak, sehingga etanol yang dihasilkan semakin tinggi.

Berdasarkan Tabel 1 dan Tabel 2 dapat diketahui bahwa nilai efisiensi fermentasi SHF1 dan SHF2 menghasilkan nilai yang berkisar 67\%. Sedangkan pada SSH menghasilkan nilai efisiensi fermentasi berkisar 83\%. Hal ini menunjukkan bahwa fermentasi secara SSF dilakukan secara optimal karena menggunakan 3 kultur campuran secara simultan yang mampu mengkonversi gula mencadi etanol secara optimal dengan waktu yang lebih singkat.

Tabel 1. Kinetika fermentasi bioetanol SHF1 dan SHF2 pada media kulit ubi kayu

\begin{tabular}{|c|c|c|c|c|c|c|c|c|c|c|c|c|c|c|}
\hline \multirow[t]{2}{*}{$\begin{array}{c}\text { Lama } \\
\text { Fementasi } \\
\text { (Jam) }\end{array}$} & \multicolumn{2}{|c|}{$\begin{array}{l}\text { Populasi } \\
\text { Yeast } \\
\text { (Log } \\
\text { cfu/ml) }\end{array}$} & \multirow[b]{2}{*}{ SHF1 } & \multicolumn{3}{|c|}{$\begin{array}{l}\text { Laju Konsumsi } \\
\text { (g/l/jam) }\end{array}$} & \multicolumn{2}{|c|}{$\begin{array}{l}\text { Growth rate } \\
\text { (/jam) }\end{array}$} & \multicolumn{2}{|c|}{$\begin{array}{c}\text { Growth yield } \\
\text { (log } \\
\mathrm{cfu} / \mathrm{ml} / \mathrm{g} / \mathrm{l})\end{array}$} & \multicolumn{2}{|c|}{$\begin{array}{l}\text { Produktivitas } \\
\text { (g/l/jam) }\end{array}$} & \multicolumn{2}{|c|}{$\begin{array}{c}\mathrm{Y} p / \mathrm{s}(\mathrm{g} \\
\text { etanol/g gula) }\end{array}$} \\
\hline & SHF1 & SHF2 & & SHF2 & SHF1 & SHF2 & SHF1 & SHF2 & SHF1 & SHF2 & SHF1 & SHF2 & SHF1 & SHF2 \\
\hline 0 & 8,32 & 8,37 & 0 & 0 & 0 & 0 & 0 & 0 & 0 & 0 & 0 & 0 & 0 & 0 \\
\hline 6 & 8,55 & 8,47 & 0,023 & 0,014 & 0,09 & 0,04 & 1,25 & 1,59 & 0,21 & 0,16 & 1,202 & 2,52 & 118,7 & 298,7 \\
\hline 12 & 8,67 & 8,65 & 0,023 & 0,014 & 0,07 & 0,05 & 1,32 & 1,17 & 0,13 & 0,12 & 0,19 & 0,55 & 22,26 & 64,89 \\
\hline 18 & 8,74 & 8,72 & 0,032 & 0,017 & 0,05 & 0,04 & 0,73 & 1,15 & 0,12 & 0,1 & 0,44 & 0,79 & 51,07 & 93,77 \\
\hline 24 & 9,07 & 9,04 & 0,028 & 0,021 & 0,07 & 0,06 & 1,13 & 1,33 & 0,11 & 0,09 & 0,58 & 0,58 & 67,85 & 67,95 \\
\hline
\end{tabular}

Tabel 2. Kinetika fermentasi bioetanol secara SSF pada kulit ubi kayu

\begin{tabular}{ccccccccc}
\hline Waktu & $\begin{array}{c}\text { Populasi } \\
\text { Yeast (Log } \\
\text { cfu/ml) }\end{array}$ & $\begin{array}{c}\text { Laju } \\
\text { Konsumsi } \\
(\mathrm{g} / \mathrm{l} / \mathrm{jam})\end{array}$ & $\begin{array}{c}\text { Growth } \\
\text { rate } \\
(/ \mathrm{jam})\end{array}$ & $\begin{array}{c}\text { Growth } \\
\text { yield }(\mathrm{log} \\
\mathrm{cfu} / \mathrm{ml} / \mathrm{g} / \mathrm{l})\end{array}$ & $\begin{array}{c}\text { Etanol } \\
(\mathrm{g} / \mathrm{l})\end{array}$ & $\begin{array}{c}\text { Produktivitas } \\
(\mathrm{g} / \mathrm{l} / \mathrm{jam})\end{array}$ & $\begin{array}{c}\text { Y p/s (g } \\
\text { etanol/g } \\
\text { gula })\end{array}$ & $\begin{array}{c}\text { Efisiensi } \\
(\%)\end{array}$ \\
\hline 0 & 8,38 & 0,000 & 0 & 0 & 0 & 0 & 0 & 0 \\
6 & 8,65 & 0,000 & 0,1 & 0 & 1,28 & 0,21 & 0 & 0 \\
12 & 8,77 & 0,000 & 0,08 & 0 & 1,9 & 0,16 & 0 & 0 \\
18 & 9,1 & 0,006 & 0,09 & 6,44 & 2,93 & 0,16 & 1,45 & 83,54 \\
24 & 9,01 & 0,009 & 0,06 & 3,25 & 2,59 & 0,11 & 1,4 & 80,71 \\
\hline
\end{tabular}




\section{KESIMPULAN}

Metode fermentasi secara SHF1 mampu menghasilkan etanol yang lebih tinggi dibandingkan SHF2. Penggunaan metode SSF mampu menghasilkan etanol lebih tinggi yaitu sebesar 2,93 g/l dengan waktu fermentasi lebih singkat yaitu 18 jam dibandingkan dengan metode SHF1 dan SHF2 yang hanya mampu menghasilkan etanol masing-masing sebesar 2,58 g/l dan 2,15 g/l dengan waktu yang dibutuhkan lebih lama yaitu 48 jam.

\section{DAFTAR PUSTAKA}

Arindhani, S. 2015. "Produksi Bioetanol Menggunakan Ragi Roti Instan Dengan dan Tanpa Pemberian Aerasi pada Media Molases". Skripsi. Universitas Jember, Jember.

Artiyani, A., E. S. Soedjono. 2011. Bioetanol dari limbah kulit singkong melalui proses hidrolisis dan fermentasi dengan Saccharomyces cerevisiae. Prosiding Seminar Nasional Manajemen Teknologi XIII. FTSP Institut Teknologi Sepuluh Nopember, Surabaya.

Assadam, A. 2014. "Delignifikasi Secara Kimia Kopi Robusta Hasil Samping Pengolahan Kopi Metode Kering Sebagai Substrat Bioetanol". Skripsi. Universitas Jember, Jember.

Badan Pusat Statistik. 2015. Produksi Ubi Kayu Sektor Pertanian di Indonesia Thun 2015. Badan Pusat Statistik, Jakarta.

BPTP. 2015. Outlook Energi Indonesia 2015. Pusat Teknologi Pengembangan Sumberdaya Energi, Jakarta.

Batubara, R. 2006. "Teknologi Pengawetan Kayu Perumahan dan Gedung dalam Upaya Pelestarian Hutan". Karya Tulis. Departemen Kehutanan, Fakultas Pertanian, Universitas Sumatera Utara, Medan.
Faiqoh, H. 2017. "Efisiensi Hidrolisis Tepung Kulit Ubi Kayu Menggunakan $T$. viride dan A. Niger". Skripsi. Universitas Jember, Jember.

Fengel, D. \& Wegener, G. 1995. Kimia Kayu, Reaksi Ultrastruktur: Terjemahan Hardjono, S. UGM Press, Yogyakarta.

Gandjar, Indrawati, Wellyzar Sjamsuridzal dan Ariyanti Oetari, 2006. Mikologi Dasar dan Terapan. Yayasan Obor Indonesia, Jakarta.

International Annual Energy Outlook. 2013. World Total Energy Consumption by Region and Fuel. Online. DOE/EIA0383(2013).

Judoamidjojo, M., Said, E. G., dan Darwis, A. A. 1992. Teknologi Fermentasi. Rajawali Press, Jakarta.

Kadita, F.D. 2016. "Produksi Bioetanol Menggunakan Ragi Komersial New Aule Instant Dry Yeast pada Media Molases secara Fed-Batch". Skripsi. Universitas Jember, Jember.

Khaidir, Setyaningsih, Haerudin. 2012. Dehidrasi bioetanol menggunakan zeolit alam termodifikasi. IPB, Bogor.

Mayzuhroh, A. 2015. "Produksi Bioetanol Menggunakan Ragi Alkohol Instan (Angel Alcohol Active Dry Yeast dan New Aule Alcohol Yeast) dengan dan Tanpa Pemberian Aerasi dan Agitasi Pada Media Molasses". Skripsi. Universitas Jember, Jember.

Nakasaki, K., and Adachi, T. 2003. Effects of intermittent addition of cellulase for production of L-lactic acid from wastewater sludge by simultaneous saccharification and fermentation. Journal Biotechnology Bioengineering, pp: 263-270.

Olofsson, K., Rudolf, A., Lidén, G. 2008. Designing simultaneous saccharification and fermentation for improved xylose conversion by a recombinant strain of Saccharomyces cerevisiae. Jurnal Biotechno., 134:112-120. 
Taherzadeh, M. J., dan K. Karimi. 2007. "Acid-Based Hydrolysis Prosesses For Ethanol From Lignocellulosic Materials". A Review. Isfahan University of Technology : Defartement of chemical engineering.

Wignyanto, Suharjono, dan Novita. 2001. Pengaruh konsentrasi gula reduksi sari hati nanas dan inokulum Saccharomyces cerevisiae pada fermentasi etanol. Jurnal Teknologi Pertanian, 2 (1): 6877. 